\title{
A New Insights on European Farming Enterprises Sustainability (book review)
}

\author{
Shengquan Che \\ Vice Director Bulgaria Center, Vice Dean School of Design, Shanghai Jiao Tong University \\ Email: chsq@sjtu.edu.cn
}

\begin{abstract}
Around the globe the understanding and assessment of the sustainability of farming enterprises is among the most topical academic and practical issues. Despite its importance there are few profound studies on sustainability of different types of farming enterprises during European Union Common Agricultural Policy (EU CAP) implementation. This book review tries to present and assess a recently published book called "Sustainability of Farming Enterprises in Bulgaria" by one of the biggest academic publishers in the world and written by an internationally recognized expert in the area - Professor Hrabrin Bachev of the Institute of Agricultural Economics in Sofia, Bulgaria. In this book, the author suggests a practical and holistic approach for assessing the sustainability of farming enterprises in the conditions of EU CAP implementation in Bulgaria. He incorporates the later developments in the area and suggests an interdisciplinary, holistic and practical approach for assessing the sustainability of farming enterprises. Particularly, he successfully includes "new" important governance and institutional aspects in the overall sustainability assessment. The first of its kind evaluation is made on integral, governance, economic, social and environmental sustainability of farming enterprises of different juridical type, size, production specialization, and ecological and geographical location in the country. Critical components enhancing or compromising the aspects and overall sustainability of farming enterprises of diverse type are also identified and perspectives for farming development in Bulgaria envisaged. In conclusion directions for further research as well as for amelioration of farm management and public intervention in the sector are elaborated. The suggested approach could be easily adapted and used by farmers and other interested parties in the country and abroad. This work is a must read and further expands on the previous studies in this important and rapidly evolving area.
\end{abstract}

Keywords: Agrarian governance, sustainability, institutional environment, market, private, collective, hybrid modes, Bulgaria.

Around the globe the understanding and assessment of the sustainability of farming enterprises is among the most topical academic and practical issues. At the current stage of development and reforming of European agriculture, the question about the level of sustainability of different types of farming enterprises during European Union Common Agricultural Policy (EU CAP) implementation is particularly topical. Despite that still there is no consensus on "what is the sustainability of farming enterprises", "what is the relationship between farm and agrarian sustainability", "which are the critical factors of farm sustainability", and "how to evaluate sustainability level of farming enterprises". There are numerous suggested and used frameworks for sustainability assessment applying a "universal" approach for "faceless" farming enterprises, without taking into consideration the environment in which they evolve, majority of them are practically unused by the farmers and managerial bodies due to difficulties in understanding and application.

A recently published book "Sustainability of Farming Enterprises in Bulgaria" by one of the biggest academic publishers in the world comes to respond to the great theoretical and practical needs for modern understanding and assessment of the sustainability of farming enterprises. It is among the few in-depth studies trying to give comprehensive insight on the sustainability of farming enterprises in the contemporary world. The monograph is a result of a long-term research done by an internationally recognized expert in the area - Professor Hrabrin Bachev of the Institute of Agricultural Economics in Sofia, Bulgaria. 
In this book, the author suggests a practical and holistic approach for assessing the sustainability of farming enterprises in the conditions of EU CAP implementation in Bulgaria. He extends his previous research on agrarian governance and sustainability, incorporates the later developments in the area, and suggests an interdisciplinary, holistic and practical approach for assessing sustainability of farming enterprises. Particularly, he successfully includes a "new" important governance and institutional aspects in the overall sustainability assessment. The new well-elaborated system for assessing the sustainability of farming enterprises for the specific Bulgarian conditions includes 12 principles, 21 criteria, 45 indicators and reference values. The presented novel approach is more comprehensive, easy to understand and facile to use in everyday managerial practice than the other available systems in the country and internationally.

Furthermore, the author goes beyond traditional theoretical analyses or assessments based on few aggregate indicators and applies his approach in a large-scale empirical study in Bulgaria. The first of its kind evaluation is made on integral, governance, economic, social and environmental sustainability of farming enterprises of different juridical type, size, production specialization, and ecological and geographical location in the country. That study is based on original micro socio-economic, behavioral, environmental, etc. data collected from the managers of 190 "typical" farms of different type and location.

The employed hierarchical framework allows not only the assessment of the sustainability level but also easy identification of critical components which enhance or compromise the aspects and overall sustainability of farming enterprises of diverse types. Thus, it addresses the practical needs of decision makers at various managerial levels - from the farm up to the policymaking. What is more, wide and comprehensive field investigation has let to specify major economic, behavioral, technological, social, institutional, political, ideological, international, etc. factors for farm enterprises sustainability, and foresee realistic perspectives for farming development in Bulgaria. Consequently, directions for further research as well as for amelioration of farm management and public intervention in the sector are elaborated in a great detail.

The book contributes significantly to the field, deepening the theoretical framework for understanding and assessment of farm sustainability, increasing the assessment precision and operationalizing the assessment system, evaluating the actual sustainability level of farming enterprises of different types in Bulgaria, and suggesting effective directions for improvement of farm management and public intervention for sustainable development of the sector. The text is also well illustrated with around 70 figures and tables, while the reference list contains a large amount of major sources in the sustainability studies. All that speaks for itself for the book's research and informative value, good figuration and modern presentation.

All data and findings in the book are presented in an excellent way, meeting all high academic standards. At the same time, the book is written in general and an easily understandable by nonprofessionals style. That makes the study interesting for reading by a large audience - from narrow specialists and experts, researchers, educators, students, farmers, businessmen, administrators, policymakers, professionals, non-governmental and international organizations, to consumers, victims, and the public at large.

The book contains a preface, introduction, three parts with nine chapters, conclusions and recommendations as well as lists of illustrations and tables.

In the first part of the book "Framework for Understanding and Assessing Sustainability of Farming Enterprises" evolution of the sustainability "concept" as an alternative ideology, a new strategy, a system characteristic, constantly evolving category, etc., and the major approaches for sustainability assessment of farming enterprises are discussed. On that base, a more adequate definition of farming enterprise's sustainability is suggested as "the ability of a particular farm to exist in time and maintain in a long-term its governance, economic, ecological and social functions in the specific socio-economic and natural environment in which it operates and evolves". Particular emphasis is made on the justification of a "new" governance aspect of farm's sustainability and on the approach for its integration in the system of assessment of the sustainability of farming enterprises. After that, a specific for the contemporary conditions of development of Bulgarian agriculture framework for assessing sustainability of farming enterprises is proposed including a system of adequate principles, criteria, indicators, and reference values. 
The second part of the book "Level of Sustainability of Bulgarian Farming Enterprises" presents a large scale approbation of the suggested framework for evaluating the overall, governance, economic, social and environmental sustainability of farming enterprises of different juridical type, size, production specialization, ecological and administrative locations in Bulgaria. The aspect and the integral sustainability levels of farming enterprises of different types, as well as the shares of farming enterprises with different sustainability levels in each category are profoundly analyzed.

The third part of the book "Factors and Perspectives of Sustainability of Farming Enterprises in Bulgaria" identifies the important ideological, economic, behavioral, educational, technological, institutional, political, international, etc. factors enhancing or deterring farming enterprises sustainability in Bulgaria, and estimate the perspectives of sustainable farming in the country.

The book ends with conclusions and directions for further research in the area and for incorporation of the suggested system of assessment in the process of improvement of farming enterprise management and forms of public intervention in the sector.

The study has found out that the overall sustainability of Bulgarian farming enterprises is at a good level, with superior levels for environmental and social sustainability, and close to the border with a low level for governance and economic sustainability. The governance and economic sustainability of farming enterprises are low because of the fact that the governance efficiency and financial stability of holdings are low which are further determined by the low comparative efficiency of short-term inputs supply in relations to alternative organizations, and the unsatisfactory profitability of own capital and overall liquidity of farms. Simultaneously despite that, the overall environmental sustainability is relatively high, the preservation of agricultural lands and the biodiversity are relatively low because of the insufficient application of recommended irrigation norms, a high level of soils water erosion, and lowered number of wild animals on farm territory.

Furthermore, there is a great variation in the sustainability levels of farming enterprises of different types and location. With the best overall sustainability are companies, cooperatives, and enterprises with a big size, holdings specialized in pigs, poultries and rabbits, with lands in protected zones and territories, and those located in non-mountainous regions with natural handicaps, and in South-Central region of the country. On the other hand, holdings which are predominately for subsistence and mix livestock are with a low sustainability.

There is also a great variation in the share of farming enterprises with different sustainability levels as every forth farming enterprise in the country is with a low sustainability and a little more than $4 \%$ are unsustainable. For the physical persons, more than a third are with a low sustainability or unsustainable at all. Every fourth of the sole traders is with a low overall sustainability, like $15 \%$ of the cooperatives, and $6 \%$ of the companies. For holdings predominately for subsistence more than a half are with a low sustainability or unsustainable, similarly to around a third of enterprises with a small size and $24 \%$ of those with a middle size. As many as $43 \%$ of the enterprises with mix-livestock are with a low sustainability and $14 \%$ are unsustainable, similarly to the enterprises specialized in vegetables, flowers and mushrooms, where $41 \%$ are with a low sustainability and $5 \%$ unsustainable. As many as $40 \%$ of all enterprises in the South-West region are with a low sustainability or unsustainable, similarly to $37 \%$ of those in the North-West region and $32 \%$ in the North-East region. A huge number (38\%) of holdings in the mountainous regions with natural handicaps are with a low overall sustainability or unsustainable, similarly to $35 \%$ of those located in the mountainous regions and every third one in the plainmountainous regions.

Factors which stimulate to the greatest extent the actions of Bulgarian farming enterprises for improving governance sustainability are: access to advisory services, professional training of manager and hired labor, personal conviction and satisfaction, positive experience of other farms, available innovations, financial capability, private contracts and agreements, and registration and certification of products, services, etc. Factors for improving economic sustainability are: market demand and prices, received direct state subsidies, market competition, financial capability, participation in public support programs, possibilities for benefits in present moment, possibilities for benefits in near future, tax preferences, possibilities for benefits in longer-term, and integration with the buyer of product. Factors for enhancing social sustainability are: personal conviction and satisfaction, social recognition of contribution, immediate benefits for other persons and groups, community initiatives and pressure in the region, access to advisory services, policies of the EU, and existing problems and risks in the region. Factors for increasing environmental sustainability are: existing problems and risks in global scale, 
official regulations, standards, norms, etc., existing problems and risks in the region, and policies of the EU.

Currently, the national and European mechanisms of regulation and support, which affect to the greatest extent economic sustainability of the most Bulgarian farming enterprises are: direct area based payments, national tops ups for products, livestock, etc., modernization of agricultural holdings, green payments, and support to semi-market farms. At the same time, the impacts of national and European policies on governance, social and environmental sustainability of Bulgarian farming enterprises are found to be relatively weak.

This book presents quite well the findings of a "study in progress" summarizing the large body of "current knowledge" and giving readers a better picture about the state of farming enterprises sustainability in Bulgaria. Nevertheless, the snapshot sustainability assessments are rarely precise having in mind the dynamic changes in socio-economic, market, institutional, natural, and international environment in which farms operate. The assessments precision could also be put into question since it is entirely based on "subjective" estimates of managers rather than incorporating other relevant information from the field tests and surveys, statistical and other data, expertise of professionals, etc.

However, the statements above do not diminish the good academic and practical value of the book. Having in mind the enormous demand for such assessments and the huge progress made by the author, the book gives a good insight on modern understanding, levels and factors of sustainability of Bulgarian farming enterprises at the current stage of development. What is more, the elaborated approach could be easily adapted and used by farmers and other interested parties in the country and abroad. This work is a must read and further expends on the previous studies of Hrabrin Bachev and other scholars in that important and rapidly evolving area of research.

\section{References}

1. H. Bachev, Sustainability of Farming Enterprises in Bulgaria, Cambridge Scholars Publishing, Published: August 1, 2018, Hardback: 230 pages (A5), Language: English, ISBN (10): 1-5275-1126-X, ISBN (13): 978-1-5275-1126-2

https://www.cambridgescholars.com/sustainability-of-farming-enterprises-in-bulgaria 